\title{
Anti-Müllerian Hormone and Inhibin-A, but not Inhibin-B or Insulin- Like Peptide-3, may be Used as Surrogates in the Diagnosis of Polycystic Ovary Syndrome in Adolescents: Preliminary Results
}

\author{
Aylin Yetim1, Çağcıl Yetim22, Firdevs Baş1,3, Oğuz Bülent Erol4, Gülnaz Çığ5, Ahmet Uçar6, \\ Feyza Darendeliler1,3
}

\author{
1/stanbul University Istanbul Faculty of Medicine, Department of Pediatrics, Division of Adolescent Medicine, Istanbul, Turkey \\ 2Biruni University Biruni Faculty of Medicine, Department of Gynecology and Obstetrics, Istanbul, Turkey \\ 3/stanbul University Istanbul Faculty of Medicine, Department of Pediatrics, Division of Pediatric Endocrinology and Diabetes, Istanbul, Turkey \\ 4Istanbul University Istanbul Faculty of Medicine, Department of Radiology, Istanbul, Turkey \\ 5/stanbul University Cerrahpaşa Faculty of Medicine, Department of Public Health, Istanbul, Turkey \\ 6Şişli Etfal Training and Research Hospital, Clinic of Pediatrics, Division of Pediatric Endocrinology and Diabetes, Istanbul, Turkey
}

\section{ABSTRACT}

Objective: Polycystic ovary syndrome (PCOS) is a common endocrine problem in adolescents with an increasing prevalence of $30 \%$. Pursuing new biomarkers with high specificity and sensitivity in the diagnosis of PCOS in adolescents is currently an active area of research. We aimed to investigate the diagnostic value of anti-Müllerian hormone (AMH), insulin-like peptide-3 (INSL3), inhibin-A (INH-A), and inhibin-B (INH-B) in adolescents with PCOS and also to determine the association, if any, between these hormones and clinical/laboratory findings related with hyperandrogenism.

Methods: The study group comprised 53 adolescent girls aged between 14.5 and 20 years who were admitted to our outpatient clinic with symptoms of hirsutism and/or irregular menses and diagnosed as having PCOS in accordance with the Rotterdam criteria. Twenty-six healthy peers, eumenorrheic for at least two years and body mass index-matched, constituted the controls. Fasting blood samples for hormones [luteinizing hormone (LH), follicle-stimulating hormone (FSH), dehydroepiandrosterone-sulfate (DHEAS), androstenedione (D4-A), total/free testosterone (T/fT), sex hormone binding globulin (SHBG), AMH, INSL3, INH-A, INH-B] were drawn after an overnight fast.

One of the important biomarkers used to confirm the diagnosis of polycystic ovary syndrome (PCOS) and to manage the treatment process in adults and adolescent patients is anti-Müllerian hormone (AMH). However, new biomarkers (inhibin-A, inhibin-B, and insulin-like peptide-3) that may be used in the diagnosis and follow-up have also been found and are in the phase of investigation.

\section{WHAT THIS STUDY ADDS?}

The levels of insulin-like peptide-3 and inhibin-B were not found to have diagnostic values in adolescents with PCOS however, it was shown that inhibin-A could be used as a new biomarker in addition to $\mathrm{AMH}$.

Results: In the PCOS group, $83 \%$ of the subjects were oligomenorrheic/ amenorrheic and $87 \%$ had hirsutism. The $\mathrm{LH}, \mathrm{LH} / \mathrm{FSH}$ ratio, total $\mathrm{T}$, fT, free androgen-index (FAl), DHEAS levels were significantly higher $(p=0.005, p=0.042$, $p=0.047, p<0.001, p=0.007, p=0.014$, respectively) and SHBG was significantly lower ( $\mathrm{p}=0.004$ ) in PCOS patients as compared to the controls. Although the INSL3 and INH-B levels showed no difference between the groups ( $p>0.05$ ), AMH and INH-A levels were found to be significantly higher in the PCOS group compared to the controls $(p<0.001, p<0.001$, respectively). In multiple linear regression analysis, WC SDS ( $p=0.028)$, $\log \mathrm{D} 4-\mathrm{A}(\mathrm{p}=0.033), \operatorname{logSHBG}(\mathrm{p}=0.031)$, and total ovarian volume $(\mathrm{p}=0.045)$ had significant effects on $\mathrm{AMH}$ levels, and $\mathrm{LH}(\mathrm{p}=0.003)$

Address for Correspondence

Aylin Yetim MD, Istanbul University Istanbul Faculty of Medicine, Department of Pediatrics, Division of Adolescent Medicine, Istanbul, Turkey

Phone: +905053690035 E-mail: aylin.yetim@istanbul.edu.tr

This study was presented in $19^{\text {th }}$ European Meeting of International Association for Adolescent Health

@ Journal of Clinical Research in Pediatric Endocrinology, Published by Galenos Publishing. 
Yetim A et al.

Anti-Müllerian Hormone and Inhibin-A Levels in Adolescents with Polycystic Ovary Syndrome

on INH-A levels. In receiver-operating characteristic analysis, the cut-off values for AMH and INH-A were $6.1 \mathrm{ng} / \mathrm{mL}$ (sensitivity $81.1 \%$ ) and $12.8 \mathrm{pg} / \mathrm{mL}$ (sensitivity $86.8 \%)$, respectively, to diagnose PCOS. When $\mathrm{AMH}$ and INH-A were used in combination, the sensitivity (96.2\%) increased.

Conclusion: INSL3 and INH-B were not found to have diagnostic value in adolescents with PCOS. On the other hand, it was shown that INH-A could be used as a new diagnostic biomarker in addition to $\mathrm{AMH}$.

Keywords: Adolescent, anti-Müllerian hormone, inhibin-A, inhibin-B, insulin-like peptide-3, polycystic ovary syndrome

Conflict of interest: None declared

Received: 11.04 .2016

Accepted: 28.04 .2016

\section{Introduction}

Polycystic ovary syndrome (PCOS) is one of the most common endocrine problems in women in their reproductive period (1). Although the prevalence of PCOS is $5-10 \%$ in adulthood, it may increase up to $30 \%$ in adolescence $(2,3)$. It is thought that this reported increased prevalence in adolescents shows a variance depending on the criteria used for the diagnosis of PCOS and arises from the polycystic appearance of the ovaries which may be observed in adolescents or from menstrual irregularities which are expected in anovulatory cycles (2). It has been shown that this rate may even increase up to $50 \%$ in obese adolescents (4).

PCOS is a syndrome rather than a disease, and it has a wide variety of symptoms and clinical presentations. The classical findings include chronic anovulation, clinical or laboratory hyperandrogenism, and a typical polycystic appearance of the ovaries on ultrasonographic examination. According to the Rotterdam criteria specified in 2003, at least two of these criteria should be present to make a diagnosis of PCOS $(5,6)$. However, it is known that the reference range of androgen levels in adolescents is different from those of adults, that the multicystic/ polycystic appearance of the ovaries may be encountered in healthy girls during this period, that anovulatory cycles may be observed for a long time after menarche, and finally, that findings including acne are observed frequently in adolescent girls $(7,8)$. Therefore, pursuing a biomarker with a high specificity and sensitivity in the diagnosis of PCOS in adolescents is currently an active area of research.

One of the important biomarkers used to confirm the diagnosis of PCOS and to manage the treatment process in adult and adolescent patients is the anti-Müllerian hormone $(\mathrm{AMH})$. However, it is possible that other biomarkers, many of which are still in the phase of investigation, may be used in the diagnosis and follow-up of PCOS. One of these is insulin-like peptide-3 (INSL3) which is a member of the relaxin/insulin family. INSL3 is produced by testicular Leydig cells in men (9). In women, it is synthesized in the ovary, particularly by the theca interna cells of antral follicles as well as by the corpora lutea and ovarian stroma, and INSL3 levels seem to reflect gonadal function $(10,11)$. INSL3 levels are similar in prepubertal and postpubertal periods, but a significant increase is observed after pubertal onset (12). Some studies show that INSL3 expression appears to change with follicle development; it is present at higher levels in small antral follicles and at lower levels as follicles become preovulatory, which suggests a correlation with follicular maturation $(13,14)$. In contrast, Hagen et al (12) reported that INSL3 levels better reflect products from large follicles rather than products from small follicles. These authors also state that INSL3 is a specific marker for theca cells surrounding larger follicles. There are studies reporting that INSL3 is significantly increased in women with PCOS $(15,16)$. INSL3 levels have also been investigated in healthy adolescents $(12,17)$, but no study has investigated the diagnostic value of INSL3 in adolescent patients with PCOS to date.

Inhibin-A (INH-A) and inhibin-B (INH-B), which are the bioactive forms of inhibins in the $\alpha$-subunit, are synthesized in the granulosa cells of the ovaries (18). It has been suggested that in normal women, the intercycle rise of follicle-stimulating hormone (FSH) is responsible for the increased secretion of INH-B from the small antral follicles in the early follicular phase, while the midcycle luteinizing hormone (LH) increase stimulates INH-A secretion from the pre-ovulatory follicle (19). In the light of this information, INH-B may be expected to increase in patients with PCOS who have large numbers of small antral follicles; INH-A levels increase as the follicle grows, and therefore they may be expected to be normal or decreased in PCOS patients. However, conflicting results have been reported in studies conducted on adult women. Some studies have shown that INH-A does not change in patients with PCOS $(20,21)$, whereas others have shown that it increases $(22,23,24)$ or decreases $(25,26,27)$. There are also similar controversial results related with INH-B levels $(20,21,27,28,29,30)$. No study to date has investigated these hormones only in the adolescent age group.

In this study, we aimed to investigate the diagnostic value of $\mathrm{AMH}$, INSL3, INH-A, and INH-B in adolescents with PCOS and also to explore the association between these hormones and the clinical/laboratory findings related with hyperandrogenism.

\section{Methods}

We studied 53 adolescent girls aged between 14.520 years who were consecutively admitted to pediatric 
endocrine outpatient clinic of Istanbul Faculty of Medicine between August 2014 to August 2015, with symptoms of hirsutism and/or irregular menses, and diagnosed as having PCOS in accordance with the Rotterdam Criteria (5). Adolescents with chronic diseases, thyroid hormone dysfunction, congenital adrenal hyperplasia, tumors, genetic syndromes and other endocrine disorders, and those who used medications that might potentially influence the biomedical assessments were excluded from the study. Twenty-six healthy peers who were followed up in the well-child and adolescent health care unit and were eumenorrheic for at least two years constituted the control group. Menstrual cycles were defined as oligomenorrhea if the cycle intervals were longer than 45 days and amenorrhea if the cycle intervals were longer than 3 months. In addition, we tried to match the two groups in terms of body mass index (BMI). A detailed medical assessment and medical history were obtained from all subjects. Birth weight and length of the participants, family history of PCOS, mothers' age at the time of her first menstruation, and family history for type 2 diabetes were also recorded. Written consent was obtained from all parents and participants. The study was approved by the Ethics Committee of Istanbul University Faculty of Medicine (no. 2421).

\section{Clinical Evaluation}

Weight and height were measured by the same physician (A.Y.) in all subjects using a wall-mounted calibrated Harpenden stadiometer (Holtain Ltd., Crymych, UK) and an electronic scale (sensitivity at $0.1 \mathrm{~kg}$ level). BMI was calculated using the following formula: $\mathrm{BMI}=$ weight $(\mathrm{kg}) /$ height $\left(\mathrm{m}^{2}\right)$. Waist circumference (WC) was measured at the midpoint between the lower margin of the last palpable rib and the top of the iliac crest using a non-stretch tape. Hip circumference $(\mathrm{HC})$ was measured around the widest portion of the buttocks with the tape parallel to the floor, and the waist to hip ratio (WHR) was evaluated. Standard deviation scores (SDS) of these measurements were calculated using national data $(31,32,33)$. The FerrimanGallwey (FG) scoring method was used to define clinical hyperandrogenism (34).

\section{Laboratory Evaluation and Biochemical Assays}

Fasting blood samples for glucose, insulin, LH, FSH, dehydroepiandrosterone sulfate (DHEAS), androstenedione (D4-A), total testosterone (T), free testosterone (fT), sex hormone-binding globulin (SHBG), AMH, INSL3, INH-A, and INH-B were drawn between 08:00-08:30 a.m., after an overnight fast. Basal 17-hydroxyprogesterone (17OHP) and cortisol levels were measured to exclude an adrenal enzyme defect; free thyroxine $\left(T_{4}\right)$ and thyroid-stimulating hormone (TSH) levels were measured to exclude a thyroid hormone defect, and prolactin level was measured to exclude intracranial pathologies. After separation, serum samples were frozen immediately and stored at $-80{ }^{\circ} \mathrm{C}$ until they were assayed. The free androgen index (FAI) was calculated using $T$ and SHBG values [FAl=100x(T/SHBG)].

Serum LH and FSH concentrations were measured using an immunochemiluminometric assay; DHEAS and $T$ levels were measured using a radioimmune assay (RIA) (Diagnostic Products Corporation, Los Angeles, CA, USA). D4-A levels were determined using a solid-phase, competitive chemiluminescent enzyme immunoassay (Siemens Healthcare Diagnostics Technical Products, USA). 17OHP and serum cortisol levels were measured using RIA and DIA immunoassays (Beckmann Coulter Company, Marseille, France and S.A. Nivelles, Belgium, respectively). SHBG levels were estimated by IRMA (Roche Diagnostic, Rotkreuz, Switzerland). Free testosterone levels were measured using an RIA (Beckman Coulter Company, Prague, Czech Republic). Serum INH-A, INH-B, AMH (AL105-I), and INSL3 (SED873Hu) levels were determined by an enzymelinked immunosorbent assay (ELISA) (Beckman Coulter Company, Webstar, USA, and USCN-life, Houston, USA). $\mathrm{LH}$ and FSH had an intra-assay coefficient of variation (CV) of $4.8-7.5 \%$ and interassay CV of $5.4-10.7 \%$, respectively. DHEAS had an intra-assay CV of 4.5 and an interassay CV of $5.5 \%$. Testosterone had an intra-assay $\mathrm{CV}$ of $4.5 \%$ and an interassay CV of $6.4 \%$. For the D4-A assay, the intra-assay CV was $3.2-9.4 \%$ and interassay CV was $4.1-15.6 \%$. For the cortisol assay, the intra-assay CV was $5.2 \%$ and interassay CV was $8.7 \%$. The $17-\mathrm{OHP}$ assay had intra-assay and interassay $\mathrm{CVs}$ of $5 \%$. For the SHBG assay, the intra-assay $\mathrm{CV}$ was $2 \%$ and interassay $\mathrm{CV}$ was $8.3 \%$. The INH-A assay had an intra-assay $\mathrm{CV}$ of $3.4-5.6 \%$ and an interassay CV of $5.5-6.7 \%$, and the INH-B assay had an intra-assay $\mathrm{CV}$ of 2.9-4.5\% and an interassay CV of 5.5-7.5\%. Values for the $\mathrm{AMH}$ assay were $1.9-4.0 \%$ (intra-assay $\mathrm{CV}$ ) and $4.5-6.0 \%$ (interassay CV). The INSL3 assay had intra-assay and interassay $\mathrm{CVs}$ of $<10 \%$ and $<12 \%$, respectively.

\section{Pelvic Ultrasound}

Ultrasound (US) examinations were performed on the same day as the hormonal and biochemical determinations. Transabdominal pelvic US scans were performed in the PCOS group prospectively by the same experienced pediatric radiologist (O.B.E.) who was blinded to the clinical and laboratory findings of the subjects. No US was done in the control group. US was performed using a conventional full bladder Logiq 6 US scanner (General Electric Co., Milwaukee, WI, USA) and a 5-MHz convex-array broad-band transducer or a 7.5-MHz linear-array small parts transducer, 
depending on age and size. The three dimensions of the uterus [total uterine length (UL), anteroposterior (AP), and transverse diameters of the corpus], endometrial thickness (ET), and the three dimensions of each ovary (longitudinal, transverse, and AP diameters) were measured. Uterine and ovarian volumes were calculated according to the formula for ellipsoid bodies: longitudinal diameter $x$ AP diameter $x$ transverse diameter $x$ 0.52. An ovary was defined as polycystic if there were 12 follicles or more, each $2-9 \mathrm{~mm}$ in diameter (35).

\section{Statistical Analysis}

SPSS version 15 (Chicago, IL, USA) was used for statistical analyses. Results are given as mean \pm SD or median [minimum-maximum]. Normality was assessed using the Kolmogorov-Smirnov test. The normality of continuous variables was examined using three different methods including variability coefficient, KolmogorovSmirnov, and skewness-kurtosis values; if two of these three methods showed normal distribution, the distribution was considered compatible with normal distribution.

Parametric and nonparametric tests were used for inter-group comparisons. Skewed data $(\mathrm{AMH}, \mathrm{INH}-\mathrm{A}$, INH-B, T, fT, SHBG, 17OHP, D4-A) were transformed to normal distributions by calculating normal logarithms and natural logarithms. Chi-square test was used for categorical variables, while student's t-test and Pearson's correlation analysis was applied for continuous variables in independent groups. The Mann-Whitney $U$ test was used for continuous variables that did not show normal distribution. The linear regression model was applied using backward stepwise method in the patients with PCOS considering $\mathrm{AMH}$, and INH-A as a dependent variable.
The candidate biomarkers that showed a significant difference in inter-group comparisons were examined using the receiver operating characteristics (ROC) curve analysis and their diagnostic values (sensitivity and specificity) were calculated. When the type-1 error level was below $5 \%$ in the evaluation of area under the curve (AUC), the diagnostic value of the test was considered statistically significant. The net sensitivity and specificity rates of the combined use of $\mathrm{AMH}$ and INH-A in the diagnosis of PCOS were calculated (36).

\section{Results}

Thirty-four percent of the patients with PCOS $(n=18)$ were amenorrheic, $49 \%(n=26)$ were oligomenorrheic, and $17 \%(n=9)$ were eumenorrheic. Hirsutism was present in $87 \%$ of the patients with PCOS ( $n=46)$, acne was present in $43 \%(n=23)$, alopecia in $25 \%(n=13)$, and acanthosis nigricans in $49 \%(n=26)$. The distribution of subjects with obesity/overweight and normal body weight was similar in the PCOS group (57\%) and control group (50\%) (BMImatched) ( $p>0.05)$.

Although the mean age of the PCOS group was slightly higher compared with the control group $(p=0.001)$, the age at the time of menarche was similar in both groups $(p=0.397)$. The birth weight SDS, birth length SDS, and BMI SDS values were similar in both groups $(p>0.05)$. The WC SDS value was statistically significantly higher in the PCOS group $(p<0.001)$. The anthropometric measurements of the patient and control groups are shown in Table 1.

The hormone levels of the PCOS and control groups are presented in Table 2. The LH, LH/FSH ratio, total T, fT, FAI, DHEAS levels were significantly higher in the PCOS group $(p=0.005, p=0.042, p=0.047, p<0.001, p=0.007, p=0.014$,

Table 1. Clinical and anthropometric findings of the polycystic ovary syndrome patients and controls

\begin{tabular}{|l|l|l|l|} 
& $\begin{array}{l}\text { PCOS patients } \\
\mathbf{n}=53\end{array}$ & $\begin{array}{l}\text { Controls } \\
\mathbf{n}=\mathbf{2 6}\end{array}$ & $\mathbf{p}$ \\
\hline Age (years) & $16.72 \pm 1.41$ & $15.18 \pm 2.00$ & 0.001 \\
\hline Menarcheal age (years) & $12.53 \pm 1.36$ & $12.27 \pm 1.09$ & 0.397 \\
\hline Birth weight SDS & $-0.28[-3.66-3.79]$ & $0.08[-2.58-1.76]$ & 0.949 \\
\hline Birth length SDS & $0.55[-2.90-1.66]$ & $0.45[-4.27-2.78]$ & 0.466 \\
\hline Weight SDS & $1.52[-2.88-6.68]$ & $0.33[-2.46-4.02]$ & 0.054 \\
\hline Height SDS & $-0.10[-3.30-2.89]$ & $-0.49[-2.57-1.50]$ & 0.278 \\
\hline BMI SDS & $1.40[-1.74-9.20]$ & $0.78[-1.99-3.14]$ & 0.096 \\
\hline WC SDS & $3.59[0.06-10.47]$ & $0.85[-0.77-4.00]$ & $<0.001$ \\
\hline FG score & $13.50[6.00-24.00]$ & - & - \\
\hline $\begin{array}{l}\text { The results are expressed as mean } \pm \text { standard deviation or median [minimum-maximum] for log transformed data, unless stated otherwise. } p<0.05 \text { was significant. } \\
\text { PCOS: polycystic ovary syndrome, SDS: standard deviation score, BMI: body mass index, WC: waist circumference, FG: Ferriman-Gallwey }\end{array}$ \\
\hline
\end{tabular}


respectively); SHBG was found to be significantly lower in the PCOS group $(p=0.004)$. Although the INSL-3 and INH-B levels showed no difference between the groups ( $p>0.05$ ), the $\mathrm{AMH}$ and INH-A levels were found to be significantly higher in the PCOS group compared with the control group $(p<0.001, p<0.001$, respectively).

\section{Correlation Analysis}

Anthropometric measurements: INSL3 level showed no significant correlation with the anthropometric measurements, whereas the AMH level had a positive correlation with WC SDS and WHR $(r=0.305, p=0.008$; $r=0.240, \quad p=0.038)$, the INH-B level demonstrated negative correlations with BMI SDS, WC SDS, WHR ( $r=-$ $0.426, p=0.001 ; r=-0.377, p=0.001 ; r=-0.242, p=0.034$, respectively), and the INH-A level had a positive correlation with WC SDS $(r=0.285, p=0.013)$. FAl was found to positively correlate with the FG score, BMI SDS, WC SDS, and WHR ( $r=0.623, p<0.001 ; r=0.535, p<0.001 ; r=0.433$, $p<0.001 ; r=0.299, p=0.014$, respectively).

Hormones: There was a negative correlation between the INSL3 level and INH-A ( $r=-0.296, p=0.009)$. AMH was found to significantly correlate with LH, DHEAS, fT, D4-A, and INH-A $(r=0.255, p=0.032 ; r=0.288, p=0.014 ; r=0.572$, $p<0.001 ; r=0.415, p=0.004 ; r=0.385, p=0.001$, respectively). The INH-A level significantly correlated with LH, LH/FSH ratio, SHBG, DHEAS, and cortisol levels in addition to $\mathrm{AMH}$ and INSL3 $(r=0.313, p=0.008 ; r=0.350, p=0.003 ; r=-0.261$, $p=0.031 ; r=0.347, p=0.003 ; r=0.359, p=0.002, r=0.385$, $p=0.001 ; r=-0.296, p=0.009$, respectively). The INH-B level was found to significantly correlate only with $\mathrm{FSH}(\mathrm{r}=0.247$, $\mathrm{p}=0.035$ ).

Ultrasonographic findings: $\mathrm{AMH}$ was found to significantly correlate with left ovarian volume and total ovarian volume $(r=0.438, p=0.002 ; r=0.346, p=0.019$, respectively). INH-A significantly correlated with right ovarian volume and total ovarian volume $(r=0.333, p=0.024$; $r=0.315, p=0.033$, respectively).

\section{Regression Analysis}

In the PCOS group, multiple linear regression analysis was performed to explore the effect of WC SDS, FSH, $\log \mathrm{D} 4-\mathrm{A}, \log \mathrm{SHBG}, \log \mathrm{T}$, and total ovarian volume on the level of $\mathrm{AMH}$. Factors that had an effect on the level of $\mathrm{AMH}$ included (adjusted R2=0.284) WC SDS ( $\beta=-0.058$, $p=0.028), \log D 4-A(\beta=0.664, p=0.033), \log S H B G(\beta=0.012$, $p=0.031)$, and total ovarian volume $(\beta=-0.495, p=0.045)$

\begin{tabular}{|c|c|c|c|}
\hline & $\begin{array}{l}\text { PCOS patients } \\
n=53\end{array}$ & $\begin{array}{l}\text { Controls } \\
n=26\end{array}$ & $p$ \\
\hline $\mathrm{LH}(\mathrm{mlU} / \mathrm{mL})$ & $10.60[3.00-79.10]$ & 7.18 [1.57-33.93] & 0.005 \\
\hline $\mathrm{FSH}(\mathrm{mlU} / \mathrm{mL})$ & $5.27 \pm 1.76$ & $5.01 \pm 2.10$ & 0.597 \\
\hline LH/FSH & 2.30 [0.63-11.30] & 1.38 [0.51-4.74] & 0.042 \\
\hline$T(n g / m L)$ & $0.44[0.16-2.21]$ & $0.36[0.05-1.91]$ & 0.047 \\
\hline $\mathrm{fT}(\mathrm{pg} / \mathrm{mL})$ & $2.68[0.83-6.32]$ & $0.95[0.49-2.30]$ & $<0.001$ \\
\hline FAI & $6.75[0.97-23.65]$ & $3.00[0.22-36.65]$ & 0.007 \\
\hline DHEA-S ( $\mu \mathrm{g} / \mathrm{dL})$ & $301.31 \pm 122.11$ & $222.37 \pm 127.62$ & 0.014 \\
\hline SHBG (ng/mL) & $7.46[2.37-37.67]$ & 14.28 [4.67-26.78] & 0.004 \\
\hline $170 \mathrm{HP}(\mathrm{ng} / \mathrm{mL})$ & $1.19[0.18-3.97]$ & - & - \\
\hline D4-A (ng/mL) & $4.50[1.41-10.00]$ & - & - \\
\hline AMH $(\mathrm{ng} / \mathrm{mL})$ & $11.02[1.66-50.60]$ & $4.06[0.93-11.96]$ & $<0.001$ \\
\hline INH-A (pg/mL) & $29.19[1.68-307.10]$ & $2.00[1.34-146.10]$ & $<0.001$ \\
\hline INH-B (pg/mL) & 61.49 [3.44-273.50] & 91.04 [16.05-153.60] & 0.236 \\
\hline INSL3 (pg/mL) & $1260.76 \pm 285.37$ & $1359.26 \pm 236.10$ & 0.132 \\
\hline Total ovarian volume $(\mathrm{mL})$ & $27.15[6.80-46.00]$ & - & - \\
\hline L ovarian volume & $13.00[2.80-28.00]$ & - & - \\
\hline R ovarian volume & $13.60[3.90-29.00]$ & - & - \\
\hline \multicolumn{4}{|c|}{$\begin{array}{l}\text { The results are expressed as mean } \pm \text { standard deviation or median [minimum-maximum] for log transformed data, unless stated otherwise. PCOS: Polycystic ovary syndrome, LH: } \\
\text { luteinizing hormone, FSH: follicle-stimulating hormone, T: total testosterone, fT: free testosterone, FAl: free androgen index, DHEAS: dehydroepiandrosterone sulfate, SHBG: sex- } \\
\text { hormone binding globulin, 170HP: 17-hydroxyprogesterone, D4-A: androstenedione, AMH: anti-Müllerian hormone, INH-A: inhibin-A, INH-B: inhibin-B, INSL3: insulin-like peptide-3 }\end{array}$} \\
\hline
\end{tabular}


(Table 3). Multiple linear regression analysis was also performed to explore the effect of $\log A M H$, INSL3, LH, logSHBG, and DHEAS on the level of INH-A. The only factor that had an effect on the level of INH-A (adjusted R2 $=0.157$ ) was LH ( $\beta=2.023, p=0.003$ ) (Table 4).

\section{Receiver Operating Characteristics Analysis for Anti-Müllerian Hormone and Inbibin-A}

ROC curve analyses were performed to determine the ability of $\mathrm{AMH}$ and $\mathrm{INH}-\mathrm{A}$ to distinguish between adolescents with PCOS and controls (Figure 1): for $\mathrm{AMH}$ AUC of $0.88, p<0.001,95 \% \mathrm{Cl}$ : [0.80-0.96]; for inhibin-A -AUC of $0.74, p=0.001,95 \% \mathrm{Cl}$ : [0.61-0.87], respectively. The cut-off value for $\mathrm{AMH}$ was $6.1 \mathrm{ng} / \mathrm{mL}$, and the cut-off value for INH-A was $12.8 \mathrm{pg} / \mathrm{mL}$ to make a diagnosis of PCOS. With these cut-off values, AMH had a specificity of $92.3 \%$ and a sensitivity of $81.1 \%$ in the diagnosis of PCOS. When INH-A was used, the specificity and sensitivity were $69.2 \%$ and $86.8 \%$, respectively. When $\mathrm{AMH}$ and INH-A were used in combination, the specificity and sensitivity were found as $65.4 \%$ and $96.2 \%$, respectively (Figure 2).

\section{Discussion}

Our study is the first study in which INH-A, INH-B, and INSL-3 levels, together with AMH levels, were examined in adolescents with PCOS. In addition, we believe it is also important to note that in this study, the cut-off values with high sensitivity and specificity rates for $\mathrm{AMH}$ and $\mathrm{INH}-\mathrm{A}$ have been determined.

WC measurement and WHR were reported to be more contributory compared with $\mathrm{BMI}$ in the diagnosis of metabolic syndrome (37). Visceral adiposity is a frequent finding in patients with PCOS, and this leads to hyperandrogenemia by way of insulin resistance $(38,39)$. In our study, there was no difference between the PCOS and control groups in terms of obesity-overweight and normal weight distribution. WC SDS and WHR levels, which indicate increased visceral adiposity in adolescents with a diagnosis of PCOS, were found to be higher in the PCOS group compared with controls. Cortet-Rudelli et al (40) reported a positive correlation between $\mathrm{FAl}$ and the rate of visceral adiposity. A positive correlation was also shown between FAI and WC SDS in our study; $\mathrm{AMH}$ and INH-A were also found to correlate with WC SDS.
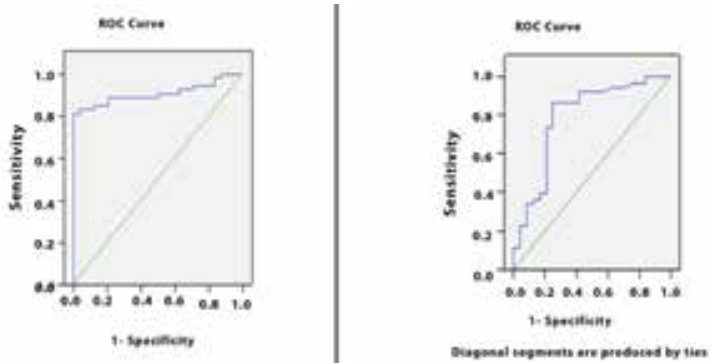

Figure 1. Receiver operating characteristics (ROC) curves of antiMüllerian hormone (left) and inhibin-A (right). The sensitivity (y axis) is plotted against the specificity (x axis)

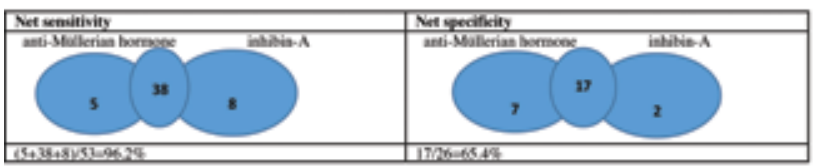

Figure 2. Net sensitivity and specificity when anti-Müllerian hormone and inhibin-A were used together

Table 3. Multiple linear regression analysis of the factors associated with logarithmic anti-Müllerian hormone in polycystic ovary syndrome group (adjusted R2 $=0.284$ )

\begin{tabular}{|l|l|l|l|l|l|}
\hline & B & SE & t & P & OR (95\% confidence interval) \\
\hline WC SDS & -0.058 & 0.025 & -2.300 & 0.028 & $-0.110-0.007$ \\
\hline $\log$ D4-A & 0.664 & 0.299 & 2.219 & 0.033 & $0.055-1.273$ \\
\hline logSHBG & 0.012 & 0.005 & 2.249 & 0.031 & $0.001-0.023$ \\
\hline Total ovarian volume & -0.495 & 0.237 & -2.089 & 0.045 & $-0.977--0.013$ \\
\hline
\end{tabular}

The variables entered in the first step of various models included waist circumference standard deviation score (WC SDS), logarithmic androstenedion (logD4-A), logarithmic sexhormone binding globulin (logSHBG), and total ovarian volume. Confidence interval $95 \%, \mathrm{p}<0.05$ was significant. SE: standard eror, OR: odds ratio

Table 4. Multiple linear regression analysis of the factors associated with logarithmic inhibin-A in polycystic ovary syndrome group (adjusted $R^{2}=0.157$ )

\begin{tabular}{|l|l|l|l|l|l|}
\hline & B & SE & $\mathbf{t}$ & $\mathbf{p}$ & OR (95\% confidence interval) \\
\hline LH & 2.023 & 0.648 & 3.122 & 0.003 & $0.719-3.328$ \\
\hline
\end{tabular}

The variables entered in the first step of various models included logarithmic anti-Müllerian hormone (logAMH), insulin-like peptide-3 (INSL3), luteinizing hormone (LH), logarithmic sexhormone binding globulin (logSHBG), and dehydroepiandrosterone sulfate (DHEAS). Confidence interval 95\%, p<0.05 was significant. SE: standard eror, OR: odds ratio 
Yetim A et al.

Anti-Müllerian Hormone and Inhibin-A Levels in Adolescents with Polycystic Ovary Syndrome

In the literature, results related to the diagnostic value of $\mathrm{AMH}$ in adolescents are conflicting. In most studies, $\mathrm{AMH}$ levels have been found to be increased in patients with PCOS $(41,42,43)$. However, some publications have shown that the increase in AMH levels was not significant (44). In our study, AMH level was found to be significantly higher in patients with PCOS than in controls. In a meta-analysis study, various values were specified for the cut-off value of $\mathrm{AMH}$. Sensitivity increased, but specificity decreased below $50 \%$ if this value was $<3 \mathrm{ng} / \mathrm{mL}$. When the cut-off value was accepted as $>5 \mathrm{ng} / \mathrm{mL}$, the specificity increased above $80 \%$ and the sensitivity decreased below $70 \%(6)$. In these studies which were conducted on adult women, the cut-off value was specified to be about $4.7 \mathrm{ng} / \mathrm{mL}$. Few studies have proposed a cut-off value for $\mathrm{AMH}$ in adolescents. Deveer et al (45) had estimated the cut off value of $\mathrm{AMH}$ for adolescents with PCOS as $6.6 \mathrm{ng} / \mathrm{mL}$. In this present study, a cut-off value of $6.1 \mathrm{ng} / \mathrm{mL}$ was shown to have a high sensitivity and specificity.

Different results have been reported in studies that examined androgens as they related with $\mathrm{AMH}$ in patients with PCOS. Some studies have shown that $\mathrm{AMH}$ closely correlated especially with testosterone $(43,46)$, and others have shown that it correlated with D4-A and FAI (47). In our study, $\mathrm{AMH}$ was found to significantly correlate with androgens such as DHEAS, fT, D4-A.

INSL3 has been suggested as a laboratory test that can be used in the diagnosis of PCOS $(16,48)$. However, these studies were conducted with adult women. In our study, adolescent girls with PCOS were compared with healthy adolescent girls, and INSL3 was not significantly different in the two groups. To date, only two studies have investigated the levels of INSL3, but these studies were conducted on healthy adolescents. Pelusi et al (17) showed that INSL3 was higher in healthy adolescents with anovulatory cycles compared with adolescents who had ovulatory cycles, but the number of subjects with anovulatory cycles was considerably limited in their study. In a study which included peripubertal healthy girls, it was proposed that INSL3 was released especially from large antral follicles (12). Accordingly, it may be thought that INSL3 has no place in the diagnosis of PCOS, but it should be noted that this study was also conducted with a limited number of subjects. In some studies, it has been reported that INSL3 was related with androgens that originate from the ovary. However, these studies were conducted on late adolescents and adults $(12,15)$. In our study, it was also found that INSL3 positively correlated with the level of $\mathrm{T}$, albeit insignificantly.

Inhibins are hormones released in the ovaries during follicular development, and their effects in patients with PCOS are still a subject of investigation. No studies have been conducted with adolescents with PCOS in this area. Studies conducted with adults have yielded controversial results. While some have shown that INH-A does not change in patients with PCOS $(20,21)$, other studies have shown an increase $(22,23,24)$, while some other studies reported a decrease $(25,26,27)$. Some studies have shown that INH-B level increases in patients with PCOS (28), whereas others have shown that it decreases (30). Overall, results generally indicate that the $\mathrm{INH}-\mathrm{B}$ level does not change markedly in PCOS patients $(20,21,23,27,29)$. It has been shown that the levels of INH-A are low in the follicular phase of ovulation, increase just after ovulation, and increase further as the follicle develops $(49,50)$. INH-B is released from small antral cells during the follicular phase $(19,21)$. It is to be expected that the level of INH$\mathrm{A}$, which is related to increased $\mathrm{LH}$ level, and the level of INH-B, which is related to increased FSH level, are variable in patients with PCOS since LH and FSH levels are also variable in these patients who mostly have an increased LH/ FSH ratio with $\mathrm{LH}$ predominance. These studies have been conducted on women with PCOS according to menstrual cycle phases, considering the periods of the menstrual cycle (21). However, patients with PCOS generally have LH predominance. Therefore, it may be expected that the level of INH-B, which is induced by $\mathrm{FSH}$, is not increased and $\mathrm{INH}-\mathrm{A}$ is increased together with increased $\mathrm{LH}$ secretion independent of the cycle in these patients who are generally oligo-/amenorrheic. Similarly, Pigny et al (23) found the level of pro- $\alpha \mathrm{C} I \mathrm{NH}-\mathrm{A}$, which has both mature and immature forms in patients with PCOS, to be significantly increased. In the adolescents with PCOS in our study, the level of INH-A was found to be considerably increased and its sensitivity was high. In addition, the level of INH-B did not show a marked difference, a finding in accordance with many other studies $(20,21,23,27,29)$. This finding may also be related to the fact that our patient group was especially composed of oligo-/amenorrheic adolescents. We think that studies comparing the INH-A and INH-B levels between eumenorrheic and oligo-/amenorrheic patients with PCOS may explain the conflicting results related with these two hormones.

The inverse correlation of the INH-B level with BMI has been shown in many studies, but it has also been pointed out that this correlation is not a specific finding for patients with PCOS $(23,40)$. In our study, the patients and control groups were specifically matched in terms of $\mathrm{BMI}$, and it was found that INH-B strongly inversely correlated with BMI SDS and WC SDS, while INH-A positively correlated with WC SDS. In a study conducted by Pigny et al (23), INH-A level inversely correlated with BMI, but its correlation with visceral adiposity was not mentioned. More studies are needed in this area. 
In our study, INH-B was found to correlate with FSH level. This correlation may be considered an expected finding for INH-B which shows an increase with FSH secretion. However, some studies have found an inverse correlation between these two hormones (20). The correlation of INH-A with $\mathrm{LH}$ level and LH/FSH ratio confirmed the findings of another study (20) and regression analysis also showed the effect of LH on INH-A in our study. Correlation analysis demonstrated that INH-A also correlated with SHBG and DHEAS. Some studies have claimed that there is no correlation between INH-A and androgens in patients with PCOS, but in those studies, the comparisons were made by examining only some androgens $(20,21,26)$. Larger scale studies are also needed in this area.

One of the limitations of our study was the fact that the ages were different in the patient and control groups. However, the fact that BMI SDS values and age of menarche were similar in the two groups, partially eliminates this limitation. Also, our control group consisted of adolescents who were eumenorrheic for at least two years. BMI-matched groups were selected to enable accurate evaluation of the hormones, because it is known that INH-B levels correlate with BMI $(21,30)$.

In conclusion, the results of this present study indicate that the levels of INSL3 and INH-B do not have diagnostic value in adolescents with PCOS. On the other hand, it was shown that INH-A could be used as a new diagnostic biomarker in addition to $\mathrm{AMH}$. Currently, we need more large-scale studies to identify biomarkers that could be helpful in adolescent cases where the diagnosis of PCOS is not definite.

\section{Acknowledgments}

We thank the nurses, Miss Saliha Yılmaz and Birsen Hacıbekiroğlu for endocrinological tests, Miss Nezihe Özdek for laboratory tests, and all personnel working in our Department of Pediatric Endocrinology for their assistance.

\section{Ethics}

Ethics Committee Approval: The Ethics Committee of Istanbul University Faculty of Medicine (no. 2421), Informed Consent: Written consent was obtained from all parents and participants.

Peer-review: Externally peer-reviewed.

\section{Authorship Contributions}

Concept: Aylin Yetim, Firdevs Baş, Feyza Darendeliler, Design: Aylin Yetim, Firdevs Baş, Feyza Darendeliler, Data Collection or Processing: Aylin Yetim, Firdevs Baş, Feyza Darendeliler, Oğuz Bülent Erol, Analysis or Interpretation: Aylin Yetim, Firdevs Baş, Feyza Darendeliler, Gülnaz Çığ,
Literature Research: Aylin Yetim, Firdevs Baş, Feyza Darendeliler, Çağcıl Yetim, Ahmet Uçar, Writing: Aylin Yetim, Firdevs Baş, Feyza Darendeliler, Çağcıl Yetim, Ahmet Uçar.

Financial Disclosure: This work was supported by Scientific Research Projects Coordination Unit of Istanbul University (Project no: 47791).

\section{References}

1. Conway G, Dewailly D, Diamanti-Kandarakis E, EscobarMorreale HF, Franks S, Gambineri A, Kelestimur F, Macut D, Micic D, Pasquali R, Pfeifer M, Pignatelli D, Pugeat M, Yildiz BO; ESE PCOS Special Interest Group. The polycystic ovary syndrome: a position statement from the European Society of Endocrinology. Eur J Endocrinol 2014;171:1-29. Epub 2014 May 21

2. Hickey M, Sloboda DM, Atkinson HC, Doherty DA, Franks S, Norman RJ, Newnham JP, Hart R. The relationship between maternal and umbilical cord androgen levels and polycystic ovary syndrome in adolescence: a prospective cohort study. J Clin Endocrinol Metab 2009;94:3714-3720. Epub 2009 Jun 30

3. Hart R, Doherty DA, Mori T, Huang RC, Norman RJ, Franks S, Sloboda D, Beilin L, Hickey M. Extent of metabolic risk in adolescent girls with features of polycystic ovary syndrome. Fertil Steril 2011;95:2347-2353. Epub 2011 Mar 29

4. Isabel-Bouzas IC, Cader SA, Leao L, Kuschnir MC, Braga C. Menstrual cycle alterations during adolescence: early expression of metabolic syndrome and polycystic ovary syndrome. J Peadiatr Adolesc Gynecol 2014;27:335-341. Epub 2014 Sep 23

5. Rotterdam ESHRE/ASRM-Sponsored PCOS consensus workshop group. Revised 2003 consensus on diagnostic criteria and long-term health risks related to polycystic ovary syndrome (PCOS). Human Reprod 2004;19:41-47.

6. Iliodromiti S, Kelsey TW, Anderson RA, Nelson SM. Can anti-Mullerian hormone predict the diagnosis of polycystic ovary syndrome? A systematic review and meta-analysis of extracted data. J Clin Endocrinol Metab 2013;98:33323340. Epub 2013 Jun 17

7. Warren-Ulanch J, Arslanian S. Treatment of PCOS in adolescence. Best Pract Res Clin Endocrinol Metab 2006;20:311-330.

8. Legro RS, Arslanian SA, Ehrmann DA, Hoeger KM, Murad $\mathrm{MH}$, Pasquali R, Welt CK; Endocrine Society. Diagnosis and treatment of polycystic ovary syndrome: an Endocrine Society clinical practice guideline. J Clin Endocrinol Metab 2013;98:4565-4592. Epub 2013 Oct 22

9. Foresta C, Bettella A, Vinanzi C, Dabrilli P, Meriggiola MC, Garolla A, Ferlin A. A novel circulating hormone of testis origin in humans. J Clin Endocrinol Metab 2004;89:59525958.

10. Nichols $N$, Binta $H$, Fields PA, Drost $M$, Chang SM, Ivell $R$, Fields MJ. Immunohistochemical localization of relaxin-like factor/insulin-like peptide-3 in the bovine corpus luteum. Ann NY Acad Sci 2005;1041:506-509.

11. Bamberger AM, Ivell $R$, Balvers $M$, Kelp B, Bamberger $C M$, Riethdorf $L$, Löning T. Relaxin-like factor (RLF): a new 
specific marker for Leydig cells in the ovary. Int J Gynecol Pathol. 1999;18:163-168.

12. Hagen CP, Mieritz MG, Nielsen JE, Anand-Ivell R, Ivell R, Juul $A$. Longitudinal assessment of circulating insulin-like peptide 3 levels in healthy peripubertal girls. Fertil Steril 2015;103:780-786. Epub 2014 Dec 13

13. Irving-Rodgers HF, Bathgate RA, Ivell $R$, Domagalski $R$, Rodgers RJ. Dynamic changes in the expression of relaxin-like factor (INSL3), cholesterol side-chain cleavage cytochrome p450, and 3beta-hydroxysteroid dehydrogenase in bovine ovarian follicles during growth and atresia. Biol Reprod 2002;66:934-943.

14. Satchell L, Glister C, Bleach EC, Glencross RG, Bicknell AB, Dai $Y$, Anand-Ivell $R$, Ivell $R$, Knight PG. Ovarian expression of Insulin- Like Peptide 3 (INSL3) and its receptor (RXFP2) during development of bovine antral follicles and corpora lutea and measurement of circulating INSL3 levels during synchronized estrous cycles. Endocrinology 2013;154:18971906. Epub 2013 Apr 1

15. Gambineri A, Patton L, Prontera O, Fanelli F, Ciampaglia W, Cognigni GE, Pagotto U, Pasquali R. Basal insulin-like factor 3 levels predict functional ovarian hyperandrogenism in the polycystic ovary syndrome. J Endocrinol Invest 2011;34:685-691. Epub 2011 May 17

16. Pelusi C, Fanelli F, Pariali M, Zanotti L, Gambineri A, Pasquali R. Parallel variations of insulin-like peptide 3 (INSL3) and antimüllerian hormone $(\mathrm{AMH})$ in women with the polycystic ovary syndrome according to menstrual cycle pattern. J Clin Endocrinol Metab 2013;98:1575-1582. Epub 2013 Aug 8

17. Pelusi C, Stancampiano M, Fanelli F, Parialli M, Gambineri A, Pasqualli R. Anti-müllerian hormone and insulin-like 3 levels in healthy normal-weight ovulatory and anovulatory eumenorrheic late adolescent females: potential early biomarkers of ovarian dysfunction? Eur J Obstet Gynecol Reprod Biol 2015;195:188-192. Epub 2015 Oct 30

18. de Kretser DM, Hedger MP, Loveland KL, Phillips DJ. Inhibins, activins and follistatin in reproduction. Hum Reprod Update 2002;8:529-541.

19. Welt CK, Smith ZA, Pauler DK, Hall JE. Differential regulation of inhibin $A$ and inhibin $B$ by luteinizing hormone, folliclestimulating hormone, and stage of follicle development. J Clin Endocrinol Metab 2001;86:2531-2537.

20. Torgac M, Kokcu A, Cetinkaya MB, Alper T, Malatyalioglu $E$. Do basal inhibin $A$ and inhibin $B$ levels have value in the diagnosis of polycystic ovary syndrome? Gynecological Endocrinology 2005:20:322-326.

21. Hauzman EE, Fancsovits $P$, Murber A, Rabe T, Strowitzki T, Papp Z, Urbancsek J. Luteal-phase inhibin A and follicularphase inhibin $B$ levels are not characteristic of patients with an elevated LH-to-FSH ratio. J Assist Reprod Genet 2006;23:141-147.

22. Anderson RA, Groome NP, Baird DT. Inhibin A and inhibin B in women with polycystic ovarian syndrome during treatment with FSH to induce mono-ovulation. Clin Endocrinol (Oxf) 1998;48:577-584.

23. Pigny $P$, Cortet-Rudelli C, Decanter C, Deroubaix D, Soudan B, Duhamel A, Dewailly D. Serum levels of inhibins are differentially altered in patients with polycystic ovary syndrome: effects of being overweight and relevance to hyperandrogenism. Fertil Steril 2000;73:972-977.

24. Pigny $P$, Desailloud $R$, Cortet-Rudelli $C$, Duhamel $A$, Deroubaix-Allard D, Racadot A, Dewailly D. Serum alpha- inhibin levels in polycystic ovary syndrome. Relationship to the serum androstenedione level. J Clin Endocrinol Metab 1997;82:1939-1943.

25. Tsiqkou A, Luisi S, De Leo V, Patton L, Gambineri A, Reis FM, Pasquali R, Petraglia F. High serum concentration of total inhibin in polycystic ovary syndrome. Fertil Steril 2008;90:1859-1863.

26. Segal S, Elmadjian M, Takeshiqe T, Karp S, Mercado R, Rivnay B. Serum inhibin A concentration in women with polycystic ovarian syndrome and the correlation to ethnicity, androgens and insulin resistance. Reprod Biomed Online. 2010;20:675-680. Epub 2010 Feb 10

27. Magoffin DA, Jakimiuk AJ. Inhibin A, inhibin B and activin A concentrations in follicular fluid from women with polycystic ovary syndrome. Hum Reprod 1998;13:26932698.

28. Lockwood GM, Muttukrishna S, Groome NP, Matthews DR, Ledger WL. Mid-follicular phase pulses of inhibin B are absent in polycystic ovarian syndrome and are initiated by successful laparoscopic ovarian diathermy: a possible mechanism regulating emergence of the dominant follicle. J Clin Endocrinol Metab 1998;83:1730-1735.

29. Laven JS, Imani B, Eijkemans MJ, de Jong FH, Fauser BC. Absent biologically relevant associations between serum inhibin B concentrations and characteristics of polycystic ovary syndrome in normogonadotrophic anovulatory infertility. Hum Reprod 2001;16:1359-1364.

30. Welt CK, Taylor AE, Martin KA, Hall JE. Serum inhibin B in polycystic ovary syndrome: regulation by insulin and luteinizing hormone. J Clin Endocrinol Metab 2002;87:55595565.

31. Neyzi O, Bundak R, Gökçay G, Günöz $H$, Furman $A$, Darendeliler F, Baş F. Reference Values for Weight, Height, Head Circumference, and Body Mass Index in Turkish Children. J Clin Res Pediatr Endocrinol 2015;7:280-293.

32. Kurtoğlu S, Hatipoğlu N, Mazıcıoğlu MM, Akın MA, Çoban D, Gökoğlu S, Baştuğ O. Body weight, length and head circumference at birth in a cohort of Turkish newborns. J Clin Res Pediatr Endocrinol 2012;4:132-139. Epub 2012 May 4

33. Unalan D, Senol V, Bayat M, Mazicioğlu MM, Ozturk A, Kurtoglu S, Hatipoglu N, Ustunbas HB. Change in waist circumference over 3 years in Turkish children and adolescents. Ann Hum Biol 2013;40:419-425. Epub 2013 May 21

34. Ferriman D, Gallwey JD. Clinical assessment of body hair growth in women. J Clin Endocrinol Metab 1961;21:1440-1447.

35. Michelmore KF, Balen AH, Dunger DB, Vessey MP. Polycystic ovaries and associated clinical and biochemical features in young women. Clin Endocrinol (Oxf) 1999;51:779-786.

36. Gordis L. Assessing the Validity and Reliability of Diagnostic and Screening Tests. In: Gordis L (ed). Epidemiology. Philadelphia, Elselvier Saunders, 2014:88-116.

37. Zimmet P, Magliano D, Matsuzawa Y, Alberti G, Shaw J. The metabolic syndrome: a global public health problem and a new definition. J Atheroscler Thromb 2005;12:295-300.

38. Oh JY, Sung YA, Lee HJ. The visceral adiposity index as a predictor of insulin resistance in young women with polycystic ovary syndrome. Obesity (Silver Spring) 2013;21:1690-1694. Epub 2013 Apr 13

39. Galuzzo A, Amato MC, Giordano C. Insulin resistance and polycystic ovary syndrome. Nutr Metab Cardiovasc Dis 2008;18:511-518. Epub 2008 Jul 25 
Yetim A et al.

Anti-Müllerian Hormone and Inhibin-A Levels in Adolescents with Polycystic Ovary Syndrome

40. Cortet-Rudelli C, Pigny P, Decanter C, Leroy M, MaunouryLefebvre C, Thomas-Desrousseaux P, Dewailly D. Obesity and serum luteinizing hormone level have an independent and opposite effect on the serum inhibin B level in patients with polycystic ovary syndrome. Fertil Steril 2002;77:281287.

41. Dursun F, Güven A, Yıldız M. Assessment of Anti-Müllerian Hormone Level in Management of Adolescents with Polycystic Ovary Syndrome. J Clin Res Pediatr Endocrinol 2016;8:55-60. Epub 2015 Jan 18

42. Pawelczak M, Kenigsberg L, Milla S, Liu YH, Shah B. Elevated serum anti-Müllerian hormone in adolescents with polycystic ovary syndrome: relationship toultrasound features. J Pediatr Endocrinol Metab 2012;25:983-989.

43. Cassar $S$, Teede HJ, Moran LJ, Joham AE, Harrison CL, Strauss BJ, Stepto NK. Polycystic ovary syndrome and anti-Müllerian hormone: role of insulin resistance, androgens, obesity and gonadotrophins. Clin Endocrinol (Oxf) 2014;81:899-906. Epub 2014 Sep 1

44. Hart R, Doherty DA, Norman RJ, Franks S, Dickinson JE, Hickey M, Sloboda DM. Serum antimullerian hormone $(\mathrm{AMH})$ levels are elevated in adolescent girls with polycystic ovaries and the polycystic ovarian syndrome (PCOS). Fertil Steril 2010;94:1118-1121. Epub 2010 Jan 8

45. Deveer M, Deveer R, Basaran O, Turkcu UO, Akbaba E, Cullu N, Turhan N, Kucuk M, Kasap B. Serum Copeptin, Pentraxin 3, Anti-Mullerian Hormone Levels With Echocardiography and Carotid Artery Intima-Media Thickness in Adolescents With
Polycystic Ovary Syndrome. J Clin Med Res 2015;7:989994. Epub 2015 Oct 23

46. Pinola P, Morin-Papunen LC, Bloiqu A, Puukka K, Ruokonen A, Järvelin MR, Franks S, Tapanainen JS, Lashen H. AntiMüllerian hormone: correlation with testosterone and oligoor amenorrhoea in female adolescence in a populationbased cohort study. Hum Reprod 2014;29:2317-2325. Epub 2014 Jul 23

47. Piouka A, Farmakiotis D, Katsikis I, Macut D, Gerou S, Panidis D. Anti-Mullerian hormone levels reflect severity of PCOS but are negatively influenced by obesity: relationship with increased luteinizing hormone levels. Am J Physiol Endocrinol Metab 2009;296:238-243.

48. Anand-Ivell R, Tremellen K, Dai Y, Heng K, Yoshida M, Knight PG, Hale GE, Ivell R. Circulating insulin-like factor 3 (INSL3) in healthy and infertile women. Hum Reprod 2013;28:3093-3102. Epub 2013 Sep 5

49. Groome NP, Illingworh PJ, O'Brien M, Cooke I, Ganesan TS, Baird DT, McNeilly AS. Detection of dimeric inhibin throughout the human menstrual cycle by two-site enzyme immunoassay. Clin Endocrinol (Oxf) 1994;40:717-723.

50. Schneyer AL, Fujiwara T, Fox J, Welt CK, Adams J, Messerlian GM, Taylor AE. Dynamic changes in the intrafollicular inhibin/activin/follistatin axis during human follicular development: relationship to circulating hormone concentrations. J Clin Endocrinol Metab 2000;85:33193330. 